\title{
Folate Supplementation during Oocyte Maturation Positively Impacts the Folate-Methionine Metabolism in Pre-Implantation Embryos
}

\section{Sikander Saini}

NDRI: National Dairy Research Institute

\section{Vishal Sharma}

NBAGR: National Bureau of Animal Genetic Resources

Shama Ansari

NDRI: National Dairy Research Institute

\section{Amit Kumar}

NDRI: National Dairy Research Institute

\section{Abhishek Thakur}

NDRI: National Dairy Research Institute

\section{Hruda Nanda Malik}

NDRI: National Dairy Research Institute

\section{Satish Kumar}

NDRI: National Dairy Research Institute

Dhruba Malakar ( $\sim$ dhrubamalakar@gmail.com )

NDRI: National Dairy Research Institute https://orcid.org/0000-0003-1911-8095

\section{Research Article}

Keywords: Folic acid, in vitro fertilization, gene expression, Folate-methionine metabolism, Preimplantation embryo, Oocyte

Posted Date: May 25th, 2021

DOl: https://doi.org/10.21203/rs.3.rs-552700/v1

License: (c) (i) This work is licensed under a Creative Commons Attribution 4.0 International License. Read Full License

Version of Record: A version of this preprint was published at Theriogenology on January 1st, 2022. See the published version at https://doi.org/10.1016/j.theriogenology.2022.01.024. 


\section{Abstract}

Folic acid is vital for DNA synthesis and methylations through one-carbon (C1) metabolism. Thus, it is essential for cell division during embryonic development. The present study investigated the effect of folic acid supplementation on oocyte maturation, blastocyst development and the expression of folate transporters as well as folate metabolism enzymes in oocytes and pre-implantation embryos of goat. Immature goat oocytes, matured in maturation medium comprising different folic acid concentrations $(0$, 10, 50, 100 and $150 \mu \mathrm{M}$ ), were in vitro fertilized and cultured. Cumulus expansion markers (Ptx3 and Ptgs2) in cumulus cells were highly upregulated after $50 \mu \mathrm{M}$ folic acid supplementation indicating higher degree of maturation. Supplementation of $50 \mu \mathrm{M}$ folic acid during oocyte maturation resulted in significantly higher blastocyst production rate, reduction in intracellular ROS levels as well as upregulation of the transcripts for folate transporters and key folate-methionine cycle enzymes in comparison to control. The present study demonstrates the existence of active folate-methionine cycle in oocytes and pre-implantation goat embryos. Supplementation of $50 \mu \mathrm{M}$ folic acid in maturation medium increases the blastocyst production rate, improves oocyte maturation, reduces ROS production as well as upregulate the expression of Folr1 and folate metabolism enzyme, Mtr.

\section{Introduction}

Folate is the group name commonly used for folic acid and its derivatives having similar activity. It is the key component of folate metabolism and functions as a coenzyme in $\mathrm{C} 1$ unit transfers during the nucleotides and amino acids synthesis, which in turn is necessary for cell divisions. Thus, high amount of folate is required when cell turnover is increased, such as in fetal development. The occurrence of neural tube defects in the newborns can be reduced by folic acid supplementation during pregnancy [1]. Addition of folic acid in maturation medium modified the redox state of oocyte, DNA methylation and oocyte quality in pigs [2, 3]. Folic acid facilitates oocyte maturation by modifying M-phase-promoting factor, mitogen-activated protein kinase pathways, spindle configuration and cortical granule migration [4]. Contrary to the positive effects, consumption of high amounts of folic acid may result in hazardous consequences. Folate is principally required for specific re-methylations following general demethylations during embryo development, but in excess it may lead to abnormal patterns of DNA methylation and anomalous embryo development. Consumption of high dose of folic acid during pregnancy was found to be associated with the decreased follicular development [5], delayed psychomotor development in newborn [6] and increased risk of asthma in the child [7]. In another study, the pups of mice kept on high folate diet showed altered expression of genes linked to neurodevelopment or autism spectrum disorder [8]. These findings support the need for optimization of the folic acid dose to improve the quality of oogenesis and to prevent the birth defects.

Folate transport across cell membranes is facilitated mainly by receptor-mediated and carrier-mediated transport mechanisms. Receptor mediated transport is mediated by the folate receptors viz. FOLR 1, 2 and $3[9,10]$. Carrier-mediated transport occurs through an ion exchange carrier protein, reduced folate carrier (RFC1) [11]. Internalized folic acid is converted to dihydrofolate (DHF) and then to tetrahydrofolate 
by dihydrofolate reductase (DHFR). Tetrahydrofolate is then eventually converted to 5methyltetrahydrofolate, which methylate homocysteine to produce methionine by the action of methionine synthase (MTR) (Fig. 1). Methionine synthase is an important enzyme which links the folate and methionine cycle together. Methionine is subsequently consumed for the synthesis of an important in vivo methylating agent named S-adenosyl-methionine (SAM) [12-14]. SAM is subsequently transformed into S-adenosylhomocysteine (SAH) followed by conversion to homocysteine by SAH-hydrolase (AHCY). Homocysteine is again methylated by 5-methyltetrahydrofolate to form methionine.

Gene expression studies revealed that mouse cumulus-oocyte complexes and oocytes dock the $R f c 1$ transcripts with low abundance in pre-implantation embryos, due to the lack of embryonic gene activation [15]. However, Folr1 mRNA was found to be present in pre-implantation embryos beginning at the 2-cell stage but was missing in oocytes and zygotes [15]. This anomalous pattern of expression advocate the presence of two different mechanisms that might be functioning in pre-implantation embryos and cumulus-oocyte complexes. Unlike mouse embryos, Folr 1 and $R f c 1$ transcripts were expressed in the oocyte and all stages of pre-implantation embryos in bovine [16]. Folr2 expression was absent in oocytes and all the stages of pre-implantation embryos in both mouse and cattle.

Previous studies clearly indicate that there is species-specific expression profile for folate transporters [15-17]. Moreover, the link between folic acid supplementation and folate metabolism enzymes is largely unclear in pre-implantation embryo. Therefore, the present study was aimed to investigate (i) the effect of different concentrations of folic acid on oocyte maturation and blastocyst development rate, and (ii) the expression profile of folate transporters and folate methionine cycle in caprine.

\section{Materials And Methods}

All chemicals and reagents were purchased from Sigma (St. Louis, MO, USA) unless stated otherwise.

\section{In vitro maturation of goat oocytes}

Goat ovaries were collected from a local slaughterhouse and transported to the laboratory in $0.9 \%$ saline solution containing $100 \mathrm{mg} / \mathrm{L}$ penicillin and $100 \mathrm{mg} / \mathrm{L}$ streptomycin at room temperature. COCs were isolated by puncturing the ovarian follicles. Isolated COCs were separated from cumulus cell by pipetting in hyaluronidase and immature oocytes as well as cumulus cells were stored in TRIzol at $-80^{\circ} \mathrm{C}$ for later use. COCs with more than three cumulus cells layers and a uniform ooplasm were used for subsequent study. Isolated COCs were in vitro matured in the conventional in vitro maturation medium (IVM) as

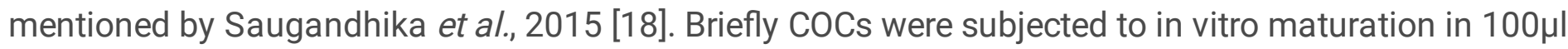
droplets (20-25 oocytes/droplet) of IVM medium (TCM-199, 10\% FBS, $5 \mu \mathrm{g} / \mathrm{ml} \mathrm{pFSH,} 1 \mu \mathrm{g} / \mathrm{ml} \beta$-estradiol, $0.81 \mathrm{mM}$ sodium pyruvate, $2.5 \mathrm{mM} \mathrm{L}$-Glutamine, $50 \mu \mathrm{g} / \mathrm{ml}$ gentamycin sulphate) for $27 \mathrm{~h}$ at $5 \% \mathrm{CO}_{2}$ and $38.5^{\circ} \mathrm{C}$. Different concentrations of folic acid $(0,50,100$ and $150 \mu \mathrm{M})$ were supplemented in the in vitro maturation medium on the basis of previous studies (Sato et al., 2013, Huang et al., 2013, McKiernan et al.,2000). COCs in each group were cultured separately. The group with zero supplementation contains 
TCM-199 having $10 \mathrm{ng} / \mathrm{ml}$ folic acid (media formulation sheet) and 10\% FBS having $43.8 \mathrm{ng} / \mathrm{ml}$ folic acid (Baker et al., 1988), making a final concentration of $13.38 \mathrm{ng} / \mathrm{ml}(30.3 \mathrm{nM})$. A fraction of matured oocytes from different folic acid supplementation groups were treated with hyaluronidase and gentle pipetting to collect cumulus cells and denuded mature oocytes for further analysis.

\section{In vitro fertilization and embryo culture}

Fresh semen was collected from a proven buck, subjected to swim-up and washed two times in sperm TALP (sp-TALP) medium. The sperms were capacitated in fertilization-TALP (fert-TALP) medium (spTALP supplemented with $10 \mu \mathrm{g} / \mathrm{ml}$ heparin and $3 \mathrm{mg} / \mathrm{ml} \mathrm{BSA}$ ) at $5 \% \mathrm{CO}_{2}$ and $37.5^{\circ} \mathrm{C}$ for $1 \mathrm{~h}$. The matured oocytes with expanded cumulus cells from different folic acid supplementation groups were coincubated with capacitated spermatozoa $\left(2 \times 10^{6} \mathrm{sperms} / \mathrm{ml}\right)$ separately in fert-TALP medium at $5 \% \mathrm{CO} 2$ and $38.5^{\circ} \mathrm{C}$ for $18 \mathrm{~h}$. The presumptive zygotes were washed to remove cumulus cells and sperms after coincubation period by gentle pipetting and subsequently cultured in modified mCR2aa (Charles Rosenkrans medium with amino acids) for 8 days post insemination in the controlled environment. The development of embryos was observed each day till the blastocyst development. 2-4 cell stage embryos, 8-16 cell stage embryos and blastocysts were collected from each supplementation groups and stored in TRIzol at $-80^{\circ} \mathrm{C}$ for further analysis.

\section{Analysis of Polar Body Rate}

After 27 hrs of in vitro maturation, the COCs from different folic acid supplementation groups $(0,10,50$, 100 and $150 \mu \mathrm{M}$ ) were collected and the cumulus cells were removed by gentle pipetting in $0.1 \%$ DPBSPVA medium. The oocytes were rinsed and stained with Hoechst 33342 for 10 min and were

subsequently washed in a couple of times in DPBS-PVP. The samples were mounted on glass slides and imaged using the inverted microscope (Olympus, Japan) fitted with epifluorescence.

\section{Relative ROS measurement}

Detection of intracellular ROS levels was performed using Carboxy-H2DFFDA (Invitrogen) according to the manufacturer's protocol. Briefly, oocytes and blastocysts were incubated for $20-30$ min at $37^{\circ} \mathrm{C}$ in DPBS supplemented with $5 \mu \mathrm{M}$ 5-(and-6)-carboxy-2', 7'-difluorodihydrofluorescein diacetate (CarboxyH2DFFDA). After a few washings in DPBS, oocytes and blastocysts were mounted on glass slides and examined using the inverted microscope (Olympus, Japan) fitted with epifluorescence. The fluorescence intensity was measured and analyzed through ImageJ software.

\section{Total RNA isolation and RT-PCR}

Total RNA was isolated from oocytes (immature and mature), cumulus cells (immature and mature), 2-4 cell stage embryos, 8-16 cell stage embryos and blastocyst using the TRIzol method using glycogen (Thermo Scientific) as carrier. First-strand cDNA was synthesized using RevertAid First Strand cDNA Synthesis Kit (Invitrogen, USA) according to the manufacturer's instructions. Gene specific primers were designed manually from the conserved regions of different exons (determined by ClustalW and BLAT) using caprine, bovine and ovine gene sequences available in KEGG. The PCR was performed on 
thermocycler (BioRad) using Dream Taq Green PCR master mix (Invitrogen, USA) according to manufacturer's instructions. The PCR reaction conditions were initial denaturation at $95^{\circ} \mathrm{C}$ for $2 \mathrm{~min}, 35$ cycles of denaturation at $95^{\circ} \mathrm{C}$ for $10 \mathrm{sec}$ followed by annealing at $62^{\circ} \mathrm{C}$ for $10 \mathrm{sec}$ and extension at $72^{\circ}$ $\mathrm{C}$ for $10 \mathrm{sec}$. Subsequently, final extension at $72^{\circ} \mathrm{C}$ for $2 \mathrm{~min}$. The amplified products were loaded onto agarose gel, electrophoresed, and photographed on Gel Doc (Bio- Rad).

\section{Quantitative reverse transcriptase PCR}

The specific primers for qRT- PCR were designed as mentioned above. Quantitative PCR was performed on LC-480 light cycler (Roche, Germany) using DyNAmo SYBR green (Thermo Fisher Scientific, USA). The program consisted of initial denaturation at $95^{\circ} \mathrm{C}$ for $2 \mathrm{~min}, 40$ cycles of denaturation at $95^{\circ} \mathrm{C}$ for $10 \mathrm{~s}$, annealing at $62^{\circ} \mathrm{C}$ for $10 \mathrm{~s}$, and extension at $72^{\circ} \mathrm{C}$ for $10 \mathrm{~s}$, with additional extension at $72^{\circ} \mathrm{C}$ for 2 min. Gapdh and Histone H2a. 1 were used as normalizing controls. Each experiment was repeated independently at least three times, and the fold change in the expression of each gene was analyzed via the $2^{-\Delta \Delta C t}$ method [19].

\section{Statistical Analysis}

Data were analyzed by one-way analysis of variance (ANOVA) with Tukey post hoc test and unpaired ttest with Welch's correction using SPSS 13.0 (SPSS, Inc.) and graphs were prepared by PRISM (GraphPad Software). All experiments were repeated at least three times. Variations between replicates are indicated with the standard error mean ( \pm SEM in error bars on graphs). Values with a $P$ value less than 0.05 were considered as statistically significant.

\section{Results}

\section{Folic acid supplementation at $50 \mu \mathrm{M}$ improves cumulus expansion}

The effect of supplementation of maturation medium with different concentrations of folic acid was studied in cumulus cells by qRT-PCR using the cumulus expansion markers (Ptgs2 and Ptx3) and Gapdh for normalization. The expression of transcripts for Ptgs2 and Ptx3 were found to be significantly upregulated in $50 \mu \mathrm{M}$ supplementation compared to other supplementation groups (Fig. 2). Moreover, the transcripts for these marker genes were significantly downregulated in $150 \mu \mathrm{M}$ supplementation group cumulus cells (Fig. 2).

\section{No effect of folic acid supplementation on polar body extrusion rate}

The extrusion of the first polar body was examined for evaluation of nuclear maturation in goat oocytes. In a total of 250 oocytes, no significant variations were observed in four replicates among the treatment groups (Fig. 3). 


\section{Folic Acid Supplementation at $50 \mu \mathrm{M}$ improves IVF Outcome}

A total of 1200 immature oocytes matured in different concentrations of folic acid from six biological replicate experiments were subjected to in vitro fertilization. Almost $78-82 \%$ cleavage rate was observed both in the folic acid supplemented groups and control. Blastocyst production rate was significantly higher $(\mathrm{P}<0.05)$ at $50 \mu \mathrm{M}$ supplementation $(21.3 \pm 0.53 \%)$ in comparison to control $(13.68 \pm 0.51 \%)$ and other supplementation groups (Fig. 4). The percentage blastocyst formation in $100 \mu \mathrm{M}(16.04 \pm 0.66 \%)$ supplementation group was significantly lower than $50 \mu \mathrm{M}$ supplementation group but no significant change was observed in comparison to control (Fig. 4). The $150 \mu \mathrm{M}$ supplementation group $(6.84 \pm 0.89$ $\%)$ showed a significant decrease in blastocyst production as compared to the other supplementation groups and control.

\section{Folic Acid Supplementation at $50 \mu \mathrm{M}$ reduces intracellular- ROS levels}

In order to determine the protective role of folic acid against oxidative stress, matured oocytes from 50 $\mu \mathrm{M}$ folic acid supplementation group and the blastocysts derived from them were collected to measure the level of intracellular ROS. Oocytes matured with $50 \mu \mathrm{M}$ folic acid and blastocysts developed from them, accumulated significantly $(14.45 \pm 1.03$ vs. $23.982 \pm 1.07, N=7, P<0.05)$ lower levels of ROS in contrast to the control group (Fig. 5).

\section{Transcripts for folate transporters and folate metabolism enzymes are present during oocyte and embryo development}

The current study details the transcript expression for genes encoding folate transporters and folate metabolism enzymes in the goat oocytes, cumulus cells and pre-implantation embryos. The gene transcripts targeted for the study were Folr1, Folr2, Rfc1, Dhfr, Ahcy and Mtr. Cumulus cells of immature and mature oocytes showed absence of transcripts for Folr1, with presence of the other five transcripts (Fig. 6). In immature and mature oocytes, the expression of transcripts for all the six genes was present. Although due to very low amount of amplified product, the band for Folr2 in mature oocytes is not clearly visible in Fig. 6. The expression of transcripts for Folr1, Folr2, Rfc1, Dhfr, Ahcy and Mtr was also present in pre-implantation embryos viz. 2-4 cell stage embryos, 8-16 cell stage embryos and blastocysts. Liver tissue was taken as positive control and showed the presence of all the six gene transcripts.

Expression of folic acid transporters and Folate-Methionine cycle enzymes varies during Embryonic

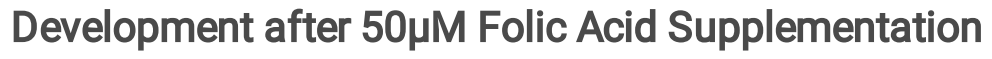

For the quantitative study of gene expression of folate transporters and Folate-Methionine cycle enzymes, qRT-PCR was carried out for Folr1, Folr2, Rfc1, Dhfr, Ahcy and Mtrgenes in mature oocytes, cumulus cells, 2-4 cell embryo, 8-16 cell embryo and blastocyst, after supplementation of $50 \mu \mathrm{M}$ folic acid in oocyte 
maturation medium (Fig. 7). Histone H2a.1 was employed for normalization. In mature oocytes, Folr1,

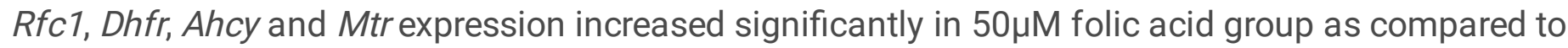
control. Correspondingly, there was significant increase in the expression of Dhfr, Ahcy and Mtr with no variation in $R f c 1$ expression in cumulus cells of mature oocytes supplemented with $50 \mu \mathrm{M}$ folic acid. The 2-4 cell stage embryos developed from the oocytes matured in $50 \mu \mathrm{M}$ folic acid showed significant increase in the expression of Folr1, Dhfr and Mtr. While there was no significant change in the expression of $R f c 1$ and $A h c y$ between control and $50 \mu \mathrm{M}$ folic acid group. No significant change in the expression of $A h c y, M t r$ and $R f c 1$ has been seen among control and folic acid supplementation group in 8-16 cell stage embryos, while Folr 1 and Dhfr increased significantly in 50 $\mu \mathrm{M}$ folic acid group. Blastocyst showed no significant difference in the expression of all the four genes between the two experimental groups. Folr2 expression was very low in mature COCs, 2-4 cell stage and 8-16 cell stage embryos to be quantified by qPCR, but measurable amount of Folr2 transcripts was detected in blastocysts with no significant variation between the supplementation group and control.

\section{Discussion}

Cumulus cells act as a vital regulator of oocyte maturation $[20,21]$ as oocytes having compromised cumulus expansion have inadequate potential for implantation [22]. This advocates the use of cumulus cells to gain comprehensive knowledge of the reproductive potential and viability of the oocytes. GDF-9 secreted by the oocyte has been reported to act as a key factor in cumulus expansion [23], which improves oocyte developmental competence by regulating several crucial granulosa cell enzymes involved in cumulus cell expansion [24]. Prostagladin-Endoperoxide Synthase 2 (Ptgs2) and Pentraxin 3 (Ptx3) are downstream GDF-9 target genes present in cumulus cells. The transcripts of these genes and others with related functions has been suggested as biomarkers of oocyte maturation [25-30]. Our results showed that at $50 \mu \mathrm{M}$ folic acid supplementation, the degree of cumulus expansion was significant (Fig. 2), which was further supported by high blastocyst development rate (Fig. 4) at this concentration. Interestingly, supplementation of $150 \mu \mathrm{M}$ folic acid decreased the expression of transcripts for Ptgs 2 as well as Ptx3, indicating towards the deleterious effects of high folic acid on oocyte maturation and developmental competence. The interaction between folic acid and GDF9 downstream pathway is not known and this study opens a new area of research.

The experiment involving the evaluation of polar body extrusion rate following oocyte maturation demonstrated no significant variation between different folic acid supplementation groups (Fig. 3). The results implies that folic acid supplementation did not improve the nuclear maturation of oocytes. On the contrary, supplementation of $50 \mu \mathrm{M}$ folic acid during oocyte maturation increases the development rate to the blastocyst stage (Fig. 4). However, there is no apparent effect of folic acid supplementation on the number of cleaved embryos. A positive effect of folic acid supplementation in maturation medium has been reported in recent studies on different animal models $[3,4,31]$. On comparison of previous studies with present study, it is noteworthy that, there are species-specific differences in the apt concentration of folic acid used for supplementation in maturation medium. The present data also shows that the development rate to the blastocyst stage greatly decreased after $150 \mu \mathrm{M}$ folic acid supplementation 
(Fig. 4), indicating towards the detrimental role of high levels of folic acid in embryo development. The results are consistent with the observations of a previous study which shows that both low and high levels of folic acid before conception is detrimental for oocyte follicular growth [5]. Even moderately high levels of folic acid supplementation in maternal diet is linked with defects in neural tube closure, embryonic delays, embryonic loss, ventricular septal defects, and thinner left and right ventricular walls and neural tube closure [32, 33]. Moreover, supplementation of $50 \mu \mathrm{M}$ folic acid during oocyte maturation decreased the intracellular ROS levels in mature oocytes (Fig. 5) signifying the potential role of folic acid as an antioxidant. In total, our work suggests that folic acid supplementation during maturation may increase the developmental competence of oocytes by influencing cytoplasmic maturation through promoting cumulus expansion and reducing ROS.

As per our knowledge, this is the first study to evaluate the dynamics of folate transporters and enzymes during pre-implantation embryo development in response to change in folate concentration during oocyte maturation. The notable observation was of Folr1, whose transcript expression significantly $(P<0.05)$ increased in mature oocytes, $2-4$ cell stage embryos and 8-16 cell stage embryos after $50 \mu \mathrm{M}$ supplementation (Fig. 7). This observation is consistent with the significant increase in blastocyst development rate (Fig. 4) and oocyte maturation at $50 \mu \mathrm{M}$ folic acid supplementation (Fig. 2). It signifies that an increased expression of Folr 1 transcripts is required for enhanced blastocyst development rate. A tendency of $R f c 1$ to express at high rates in oocytes during maturation in the presence of $50 \mu \mathrm{M}$ folic acid and returning to default levels at subsequent stages has been observed. RFC1 may possibly be acting as transport channel to fill the internal folic acid stores of oocytes during maturation for later cell divisions. On the contrary, the levels of Folr 1 transcripts remain consistently elevated throughout the developmental stages, which indicates that Folr1 may be additionally involved in other vital pathways except performing solely as folate transporter.

DHFR (Dihydrofolate Reductase) catalyses THF (Tetrahydrofolate) regeneration by reduction of dihydrofolate, and is a target for the antifolate chemotherapeutic drug MTX (Methotrexate). In the present study, the upregulation of Dhfrtranscripts observed in oocytes, cumulus and pre-implantation embryos (Fig. 7), after the folic acid supplementation, may be the result of elevated levels of internal folic acid (due to increased Folr1 and Rfc1 expression) which was needed to be further metabolized in cells. AHCY (adenosylhomocysteinase), which converts S-Adenyl-L-homocysteine to adenosine and homocysteine, was also found to be upregulated in oocytes and cumulus. The resulting adenosine is required for energy transfer via ATP and ADP as well as in signal transduction by cAMP [34]. Similarly, Methionine synthase, MTR, is necessary for normal development of the embryo by metabolizing the potentially harmful homocysteine and production of SAM [35]. In present study, the upregulation of Mtr by several folds in oocytes, cumulus and 2-4 cell stage embryos after folic acid supplementation in oocyte maturation medium probably ensures a check on the levels of homocysteine produced by AHCY. The elevated levels of Folr1 and Mtr in developmental stages, higher maturation and higher blastocyst production after 50 $\mu \mathrm{M}$ folic acid supplementation indicates a vital role of these two genes in oocyte maturation and embryo development. Moreover, homozygous Mtr knockout mice pups failed to survive after birth thereafter [36]. Folr1 and Mtr expression can thus be used for assessment of embryo quality. These results infer that 
folate supplementation improved the overall folate-methionine cycle metabolism inside the cells resulting in better embryonic metabolism and development. The exhaustion of cellular folic acid as the embryos approaches blastocyst stage may have resulted in unaltered expression of Folr1, Rfc1, Dhfr, Ahcy and Mtr. Therefore, a study involving supplementation of folic acid throughout pre-implantation embryo development is also required to deeply deduce the pathway.

In our study, the caprine oocytes (mature and immature) and pre-implantation embryos were found to express transcripts for Folr1, Folr2 and Rfc1 (Fig. 6). Although, the expression of Folr2 was very low in mature oocytes, mature cumulus cells, $2-4$ cell stage embryos and 8-16 cell stage embryos, as indicated by very faint bands (Fig. 6). The specific reason for comparatively high Folr2 expression only in blastocysts cannot be explained because of the lack of any specific function known to be associated with Folr2 except for the folic acid transport. It is noteworthy that cumulus cells of immature as well as mature oocytes expressed Folr2, but not Folr1. The RT-PCR expression patterns of folate transporters for caprine oocytes, cumulus cells and pre-implantation embryos in present study partially disagree with the results previously reported for cow and mice $[15,16]$. Kwong et al. reported that bovine $R f c 1$ is present in oocytes and pre-implantation embryos, comparable to the pattern we found in goat. Moreover, the expression of bovine Folr 1 was found to be present in oocytes and pre-implantation embryos [16]; however, in mice its expression was absent in mature oocyte and 1-cell stage embryo [15]. In the present study, transcripts for Folr 1 were detected in all the stages starting from oocyte (mature as well as immature) to blastocyst, except for cumulus cells. Contrary to the bovine and murine orthologue, caprine Folr2 was present in all the stages from oocyte to blastocyst. Human embryonic stem cells, which are analogous to the blastocyst inner cell mass, express Folr1 but not Folr2 [37], inconsistent with the expression pattern we found in goat blastocyst. Therefore, a species-specific variation can be concluded to exist in the folate transport. These differences may have been appeared evolutionarily due to the variations of folate levels in natural diet of different species. Detailed studies are required to gain the knowledge behind this observation.

\section{Conclusion}

In conclusion, supplementation of $50 \mu \mathrm{M}$ folic acid in oocyte maturation medium significantly increases the blastocyst development rate. However, folic acid at $150 \mu \mathrm{M}$ supplementation significantly reduces the blastocyst development rate. It can be summarized that higher as well as lower folic acid concentrations are detrimental for blastocyst production. Supplementation with $50 \mu \mathrm{M}$ folic acid also increased the maturation of oocytes as indicated by the high expression of cumulus expansion molecular markers (Ptx3 and Ptgs2) along with reducing intracellular ROS production. All the key enzymes of folatemethionine cycle and folate transporters are present in the pre-implantation developmental stages with measurable activities. The study also proposes the use of Folr1 and Mtr as probable markers for defining embryo quality.

Although, the present study partially helped to elucidate the function of folic acid, folate receptors and folate-methionine cycle enzymes in pre-implantation development, however many more questions are 
raised by this study such as (i) what will be the effect of supplementation of physiological forms of folate in oocyte maturation medium and embryo culture medium? (ii) Why there are differences in the expression of folate transporters among different species? (iii) How high folic acid supplementation decreases the oocyte competence? (iv) What will be the effect of folic acid supplementation throughout pre-implantation development?

\section{Declarations}

Ethical approval and informed consent. Ethical approval was taken from Institute ethics committee, ICARNational Dairy Research Institute (NDRI), Karnal, India for the present study.

Funding. No external funding except the institutional general financial support.

Conflicts of interest. The authors declare that there is no conflict of interest that would prejudice the impartiality of this scientific work.

Availability of data and material. Data sets shall be provided by the corresponding author on request. Not applicable for materials.

Code availability. Not Applicable

Authors' contributions. SS: Study concept and design, experiments execution and data analysis; SA: statistical analysis of data; VS, AK and AT: assistance in experiments; HNM and VS: review of manuscript; SK and DM: overall guidance, manuscript preparation.

Acknowledgements. The research work was supported by Indian Council of Agricultural Research (ICAR), Government of India. We would also like to thank Indian Council of Medical Research (ICMR), India; Council of Scientific and Industrial Research (CSIR), India; and Department of Biotechnology (DBT), India for providing the financial assistance in the form of fellowships to the authors.

\section{References}

1. Wald N, Sneddon J, Densem J FC and SR (1991) Prevention of neural tube defects: Results of the Medical Research Council Vitamin Study. Lancet. https://doi.org/10.1016/0140-6736(91)90133-A

2. Eun SK, Jin SS, Jin HE, et al (2009) The effect of folic acid on in vitro maturation and subsequent embryonic development of porcine immature oocytes. Mol. Reprod. Dev.

3. Sato D, Sakurai K, Monji Y, et al (2013) Supplementation of maturation medium with folic acid affects DNA methylation of porcine oocytes and histone acetylation of early developmental stage embryos. J Mamm Ova Res. https://doi.org/10.1274/jmor.30.109

4. Huang X, Gao S, Xia W, et al (2013) Folic acid facilitates in vitro maturation of mouse and Xenopus laevis oocytes. Br J Nutr. https://doi.org/10.1017/S0007114512003248 
5. Boxmeer JC, Steegers-Theunissen RPM, Lindemans J, et al (2008) Homocysteine metabolism in the pre-ovulatory follicle during ovarian stimulation. Hum Reprod. https://doi.org/10.1093/humrep/den292

6. Valera-Gran D, García De La Hera M, Navarrete-Muñoz EM, et al (2014) Folic acid supplements during pregnancy and child psychomotor development after the first year of life. JAMA Pediatr. https://doi.org/10.1001/jamapediatrics.2014.2611

7. Whitrow MJ, Moore VM, Rumbold AR, Davies MJ (2009) Effect of supplemental folic acid in pregnancy on childhood asthma: A prospective birth cohort study. Am J Epidemiol. https://doi.org/10.1093/aje/kwp315

8. Barua S, Kuizon S, Chadman K, et al (2015) Microarray Analysis Reveals Higher Gestational Folic Acid Alters Expression of Genes in the Cerebellum of Mice Offspring-A Pilot Study. Brain Sci. https://doi.org/10.3390/brainsci5010014

9. Antony AC (1992) The biological chemistry of folate receptors. Blood

10. Antony AC (1996) Folate receptors. Annu. Rev. Nutr.

11. Assaraf YG, Sierra EE, Babani S, Goldman ID (1999) Inhibitory effects of prostaglandin A1 on membrane transport of folates mediated by both the reduced folate carrier and ATP-driven exporters. Biochem Pharmacol. https://doi.org/10.1016/S0006-2952(99)00227-0

12. Loenen WAM (2006) S-Adenosylmethionine: jack of all trades and master of everything? Biochem Soc Trans. https://doi.org/10.1042/bst0340330

13. McNulty H, Pentiev K, Hoey L, et al (2012) Nutrition throughout life: Folate. Int J Vitam Nutr Res. https://doi.org/10.1024/0300-9831/a000130

14. Anderson OS, Sant KE, Dolinoy DC (2012) Nutrition and epigenetics: An interplay of dietary methyl donors, one-carbon metabolism and DNA methylation. J. Nutr. Biochem.

15. Kooistra M, Trasler JM, Baltz JM (2013) Folate transport in mouse cumulus-oocyte complexes and preimplantation embryos. Biol Reprod. https://doi.org/10.1095/biolreprod.113.111146

16. Kwong WY, Adamiak SJ, Gwynn A, et al (2010) Endogenous folates and single-carbon metabolism in the ovarian follicle, oocyte and pre-implantation embryo. Reproduction. https://doi.org/10.1530/REP09-0517

17. Meredith M, MacNeil AH, Trasler JM, Baltz JM (2016) Growing mouse oocytes transiently activate folate transport via folate receptors as they approach full size. Biol Reprod. https://doi.org/10.1095/biolreprod.115.137687

18. Saugandhika S, Sharma V, Malik H, et al (2015) Expression and purification of buffalo interferon-tau and efficacy of recombinant buffalo interferon-tau for in vitro embryo development. Cytokine. https://doi.org/10.1016/j.cyto.2015.03.012

19. Livak KJ, Schmittgen TD (2001) Analysis of relative gene expression data using real-time quantitative PCR and the 2- $\Delta \Delta C T$ method. Methods. https://doi.org/10.1006/meth.2001.1262 
20. Dekel N, Beers WH (1980) Development of the rat oocyte in vitro: Inhibition and induction of maturation in the presence or absence of the cumulus oophorus. Dev Biol. https://doi.org/10.1016/0012-1606(80)90160-8

21. Larsen WJ, Wert SE, Brunner GD (1986) A dramatic loss of cumulus cell gap junctions is correlated with germinal vesicle breakdown in rat oocytes. Dev Biol. https://doi.org/10.1016/00121606(86)90187-9

22. Sparks A (2000) An Atlas of Human Gametes and Conceptuses: An Illustrated Reference for Assisted Reproductive Technology. J Urol. https://doi.org/10.1097/00005392-200009010-00072

23. Elvin JA, Clark AT, Wang P, et al (1999) Paracrine actions of growth differentiation factor-9 in the mammalian ovary. Mol Endocrinol. https://doi.org/10.1210/mend.13.6.0310

24. Pangas SA, Matzuk MM (2005) The art and artifact of GDF9 activity: Cumulus expansion and the cumulus expansion-enabling factor. Biol. Reprod.

25. McKenzie LJ, Pangas SA, Carson SA, et al (2004) Human cumulus granulosa cell gene expression: A predictor of fertilization and embryo selection in women undergoing IVF. Hum Reprod. https://doi.org/10.1093/humrep/deh535

26. Cillo F, Brevini TAL, Antonini S, et al (2007) Association between human oocyte developmental competence and expression levels of some cumulus genes. Reproduction. https://doi.org/10.1530/REP-07-0182

27. Feuerstein P, Cadoret V, Dalbies-Tran R, et al (2007) Gene expression in human cumulus cells: One approach to oocyte competence. Hum Reprod. https://doi.org/10.1093/humrep/dem336

28. Anderson RA, Sciorio R, Kinnell $\mathrm{H}$, et al (2009) Cumulus gene expression as a predictor of human oocyte fertilisation, embryo development and competence to establish a pregnancy. Reproduction. https://doi.org/10.1530/REP-09-0144

29. Gebhardt KM, Feil DK, Dunning KR, et al (2011) Human cumulus cell gene expression as a biomarker of pregnancy outcome after single embryo transfer. Fertil Steril. https://doi.org/10.1016/j.fertnstert.2011.04.033

30. Wathlet S, Adriaenssens T, Segers I, et al (2011) Cumulus cell gene expression predicts better cleavage-stage embryo or blastocyst development and pregnancy for ICSI patients. Hum Reprod. https://doi.org/10.1093/humrep/der036

31. Szymański W, Kazdepka-Ziemińska A (2003) Effect of homocysteine concentration in follicular fluid on a degree of oocyte maturity. Ginekol Pol

32. Marean A, Graf A, Zhang Y, Niswander L (2011) Folic acid supplementation can adversely affect murine neural tube closure and embryonic survival. Hum Mol Genet. https://doi.org/10.1093/hmg/ddr289

33. Mikael LG, Deng L, Paul L, et al (2013) Moderately high intake of folic acid has a negative impact on mouse embryonic development. Birth Defects Res Part A - Clin Mol Teratol. https://doi.org/10.1002/bdra.23092

34. Morton IKM, Hall JM (1999) Concise Dictionary of Pharmacological Agents 
35. Padmanabhan N, Jia D, Geary-Joo C, et al (2013) XMutation in folate metabolism causes epigenetic instability and transgenerational effects on development. Cell.

https://doi.org/10.1016/j.cell.2013.09.002

36. Swanson DA, Liu M-L, Baker PJ, et al (2001) Targeted Disruption of the Methionine Synthase Gene in Mice. Mol Cell Biol. https://doi.org/10.1128/mcb.21.4.1058-1065.2001

37. Steele W, Allegrucci C, Singh R, et al (2005) Human embryonic stem cell methyl cycle enzyme expression: Modelling epigenetic programming in assisted reproduction? Reprod Biomed Online. https://doi.org/10.1016/S1472-6483(10)61120-0

\section{Figures}

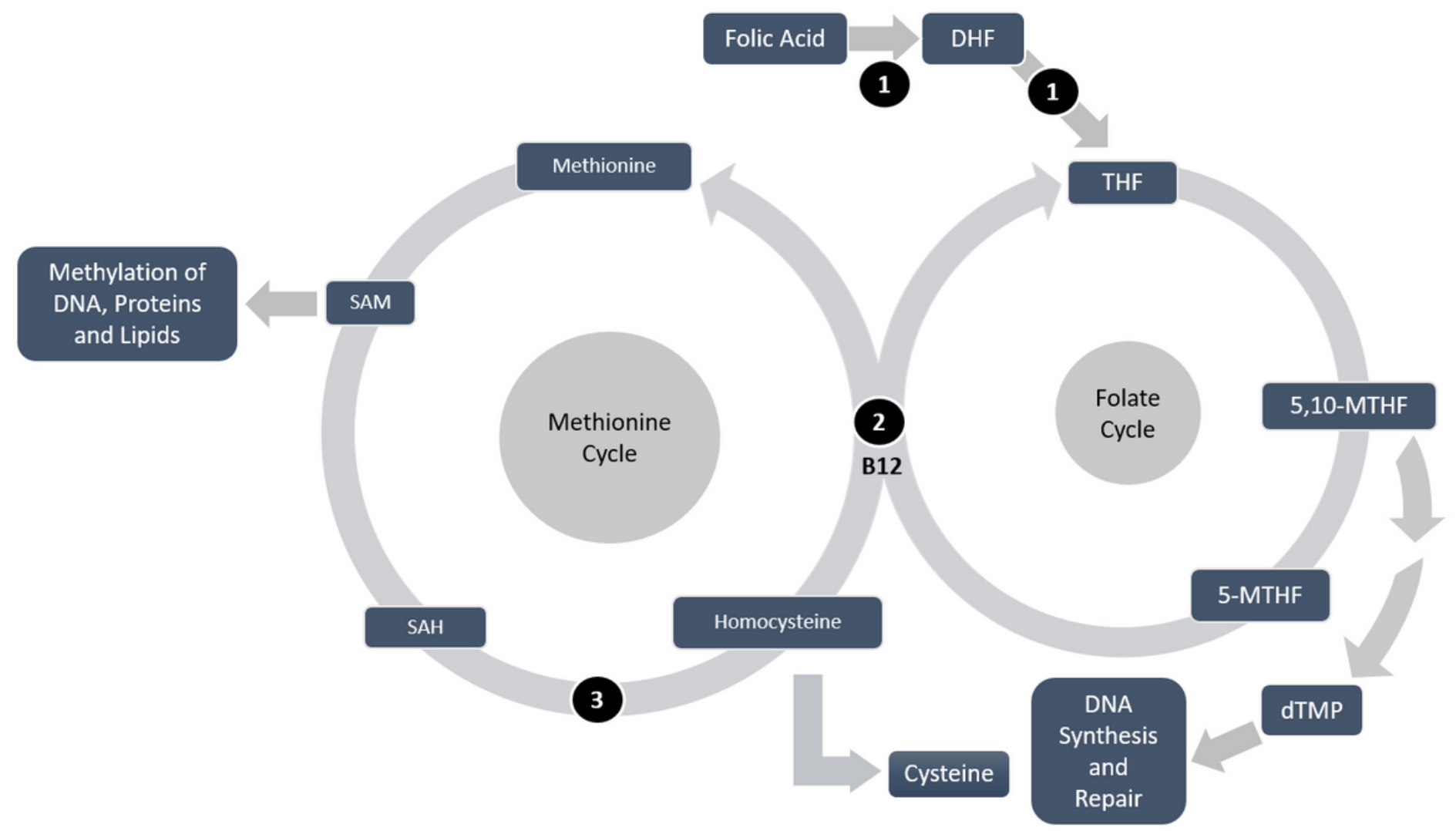

\section{Figure 1}

Folate-methionine cycle displaying key metabolites and enzymes used in the study. Metabolites: dihydrofolate (DHF), tetrahydrofolate (THF), methyl tetrahydrofolate (MTHF), methylcobalamin (B12), Sadenosylmethionine (SAM), S-adenosylhomocysteine (SAH), Enzymes: dihydrofolate reductase (DHFR) (1), methionine synthase (MTR) (2), SAH-hydrolase (AHCY) (3) 


\section{Cumulus maturation}

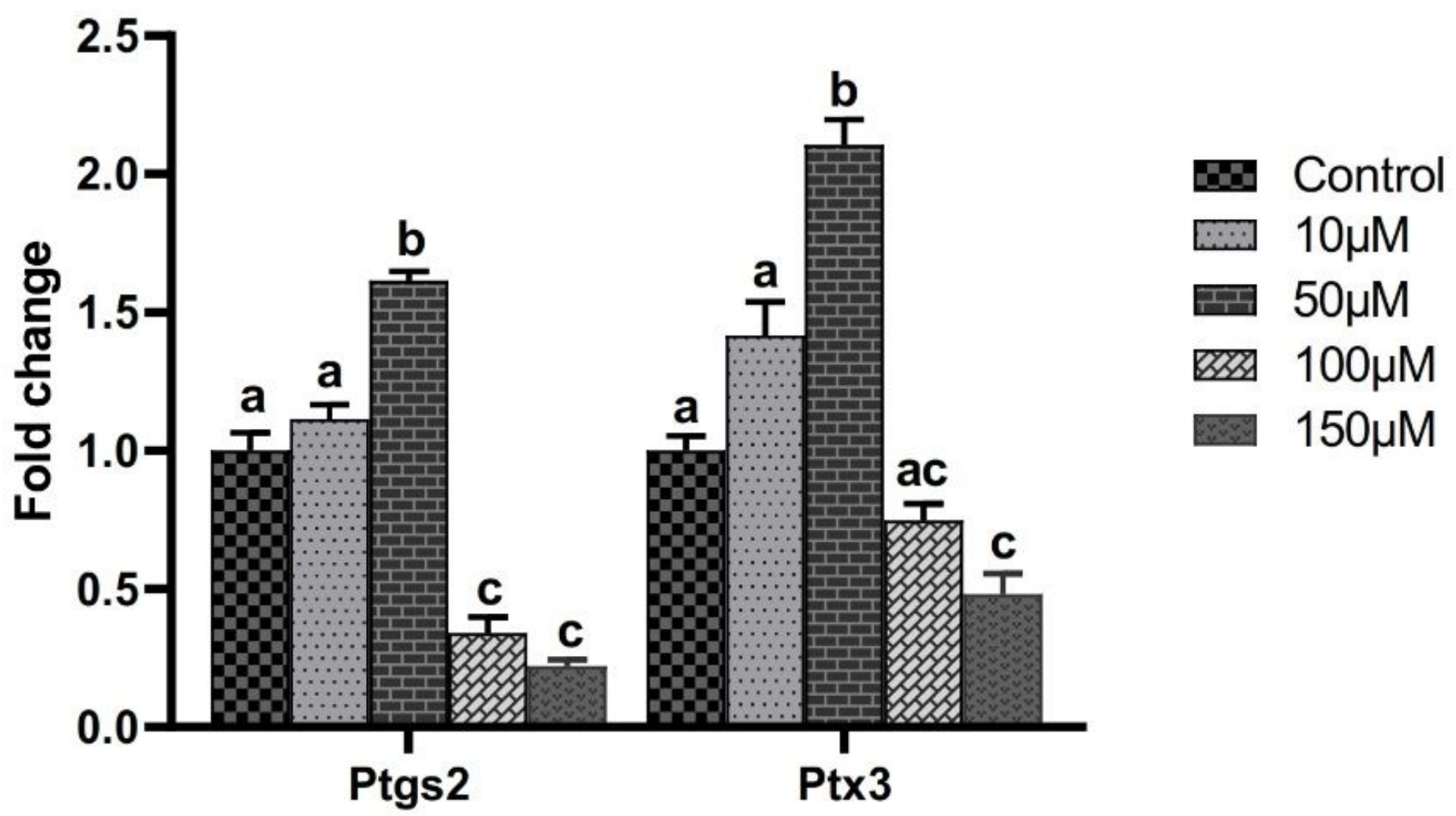

Figure 2

qRT-PCR of markers of cumulus expansion on cumulus cells of matured oocytes. The expression of maturation markers (Ptgs2 and Ptx3) in cumulus cells of oocytes matured in control $50 \mu \mathrm{M}, 100 \mu \mathrm{M}$ and $150 \mu \mathrm{M}$ folic acid supplementation in medium and control medium. Vertical axis represents the fold change in gene expression and horizontal axis represents the genes at control and folic acid supplementations. Bars represent mean number of transcripts ( \pm SEM) of $N=3$ repeats. Bars that do not share the same letter are significantly different $(P<0.05)$ by one-way ANOVA with Tukey post hoc test. 


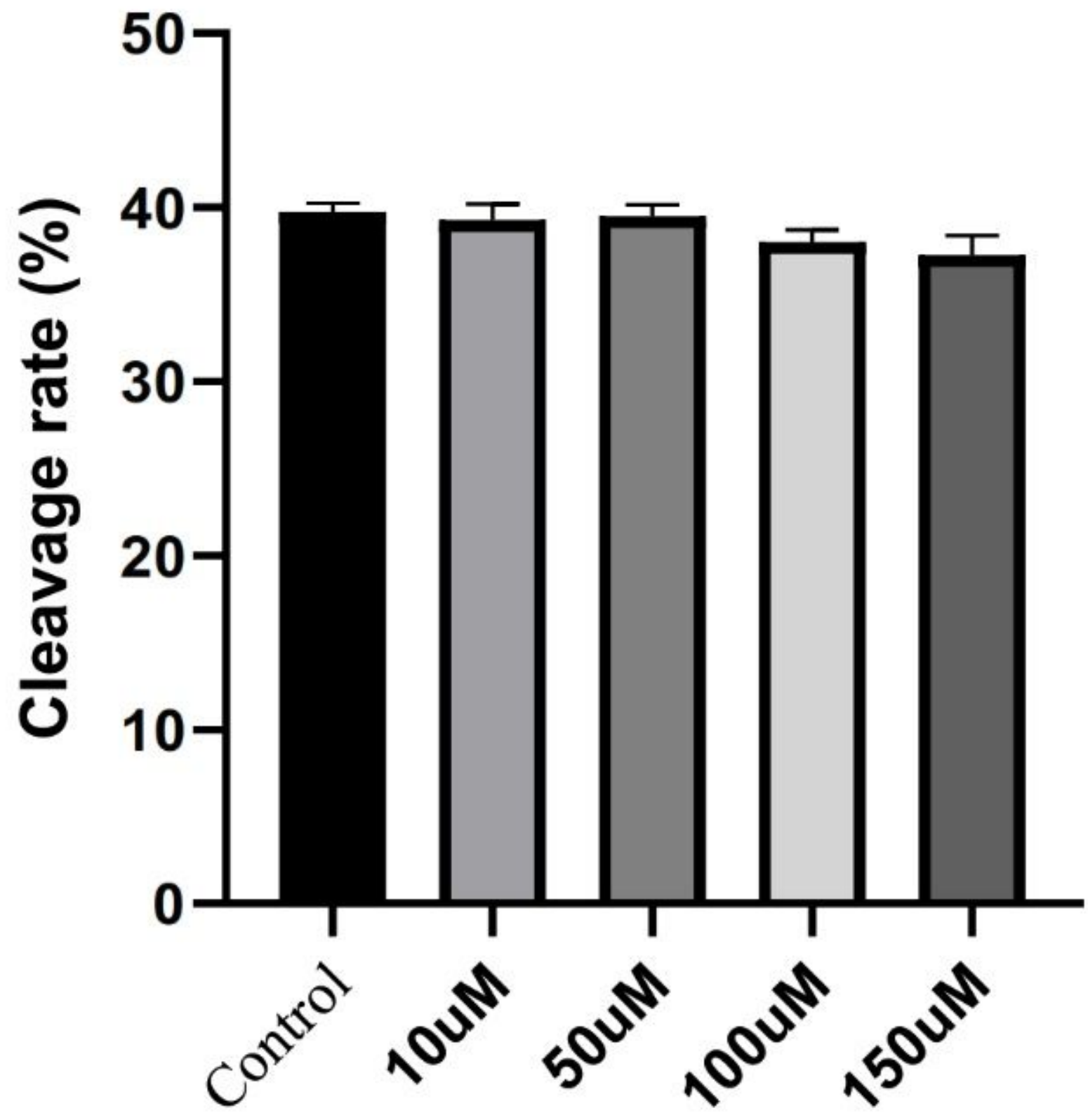

Folic acid supplementation groups

Figure 3

Effect of supplementation of maturation medium with folic acid on polar body extrusion rate. No significant difference between folic acid supplementation groups. SEM- standard error of the mean of $\mathrm{N}=$ 4 repeats. 


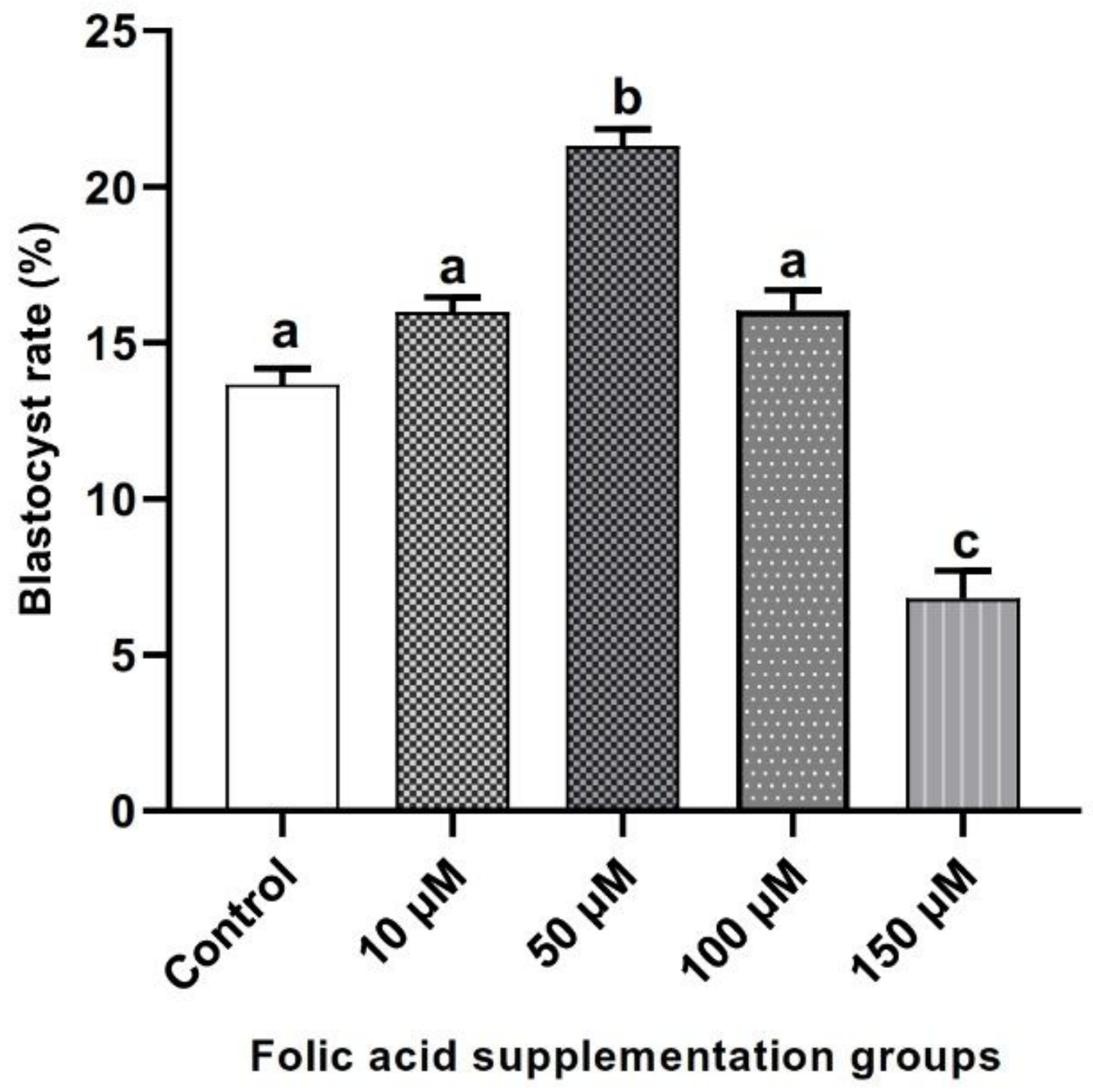

Figure 4

Effect of supplementation of maturation medium with folic acid on the rate of blastocyst production. Bars that do not share the same letter are significantly different $(P<0.05)$ by one-way ANOVA with Tukey post hoc test. SEM- standard error of the mean of $\mathrm{N}=6$ repeats. 


\section{ROS level in Oocytes}

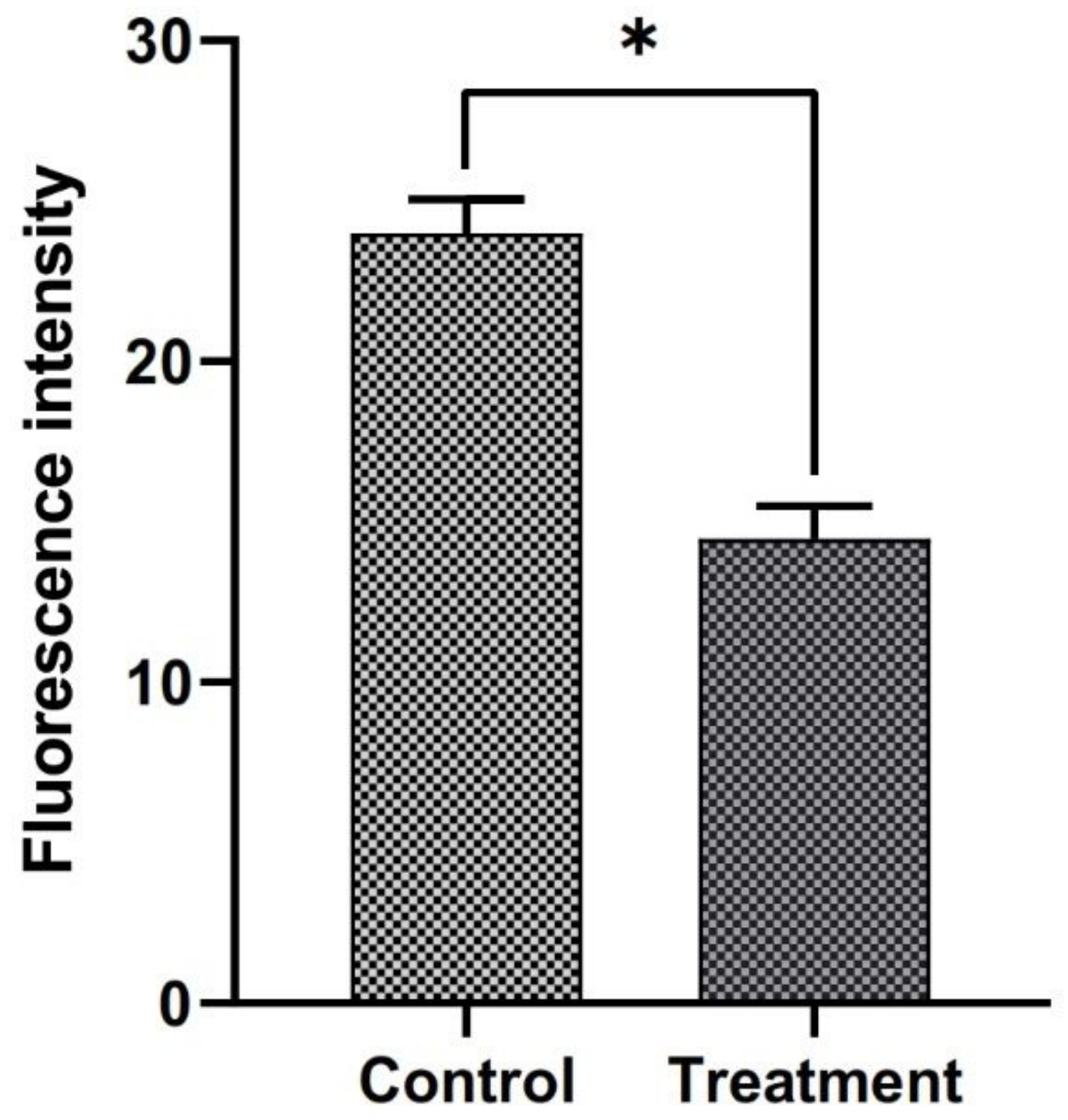

Figure 5

Effect of supplementation of maturation medium with $50 \mu \mathrm{M}$ folic acid on intracellular ROS levels.

Asterisk (*) mark represents the bar with significant difference by Unpaired t-test with Welch's correction. Treatment is referred to $50 \mu \mathrm{M}$ folic acid supplementation $(14.45 \pm 1.03$ vs. $23.982 \pm 1.07, \mathrm{P}<0.05)$. SEMstandard error of the mean of $\mathrm{N}=7$ repeats 


\section{M10 M1C M2O M2C $\quad 2-4 C \quad 8-16 C$ BL LV NC}

Folr1

Folr2

Rfc1

Dhfr

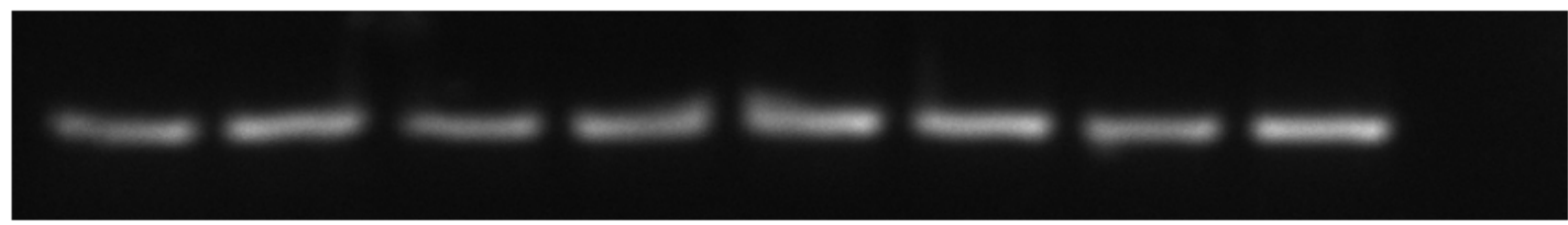

Mtr

Ahcy

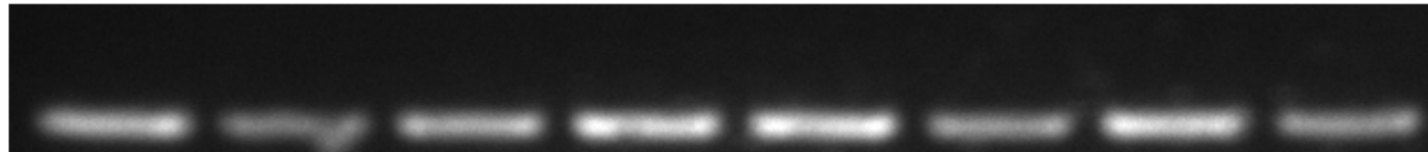

\section{Gapdh}

\section{Figure 6}

Expression of folate transporters mRNA. RT-PCR detection of Folr1, Folr2, Rfc1, Dhfr, Mtr, Ahcy and Gapdh (control) mRNA in immature oocytes (M10), cumulus cells of immature oocytes (M1C), mature oocytes (M2O), cumulus cells of mature oocytes (M2C), 2-4 cell stage embryos (2-4C), 8-16 cell stage embryos (8$16 \mathrm{C})$, blastocysts (BL), goat liver tissue +ve control (LV) and Negative control (NC, Reaction control). Very faint bands of Folr1 in M2O, M2C, 2-4C and 8-16C were present. Each lane contains 0.3 equivalent of oocyte or embryo per PCR reaction, except $0.5 \mu \mathrm{g}$ and $1 \mu \mathrm{g}$ cDNA for Liver. 

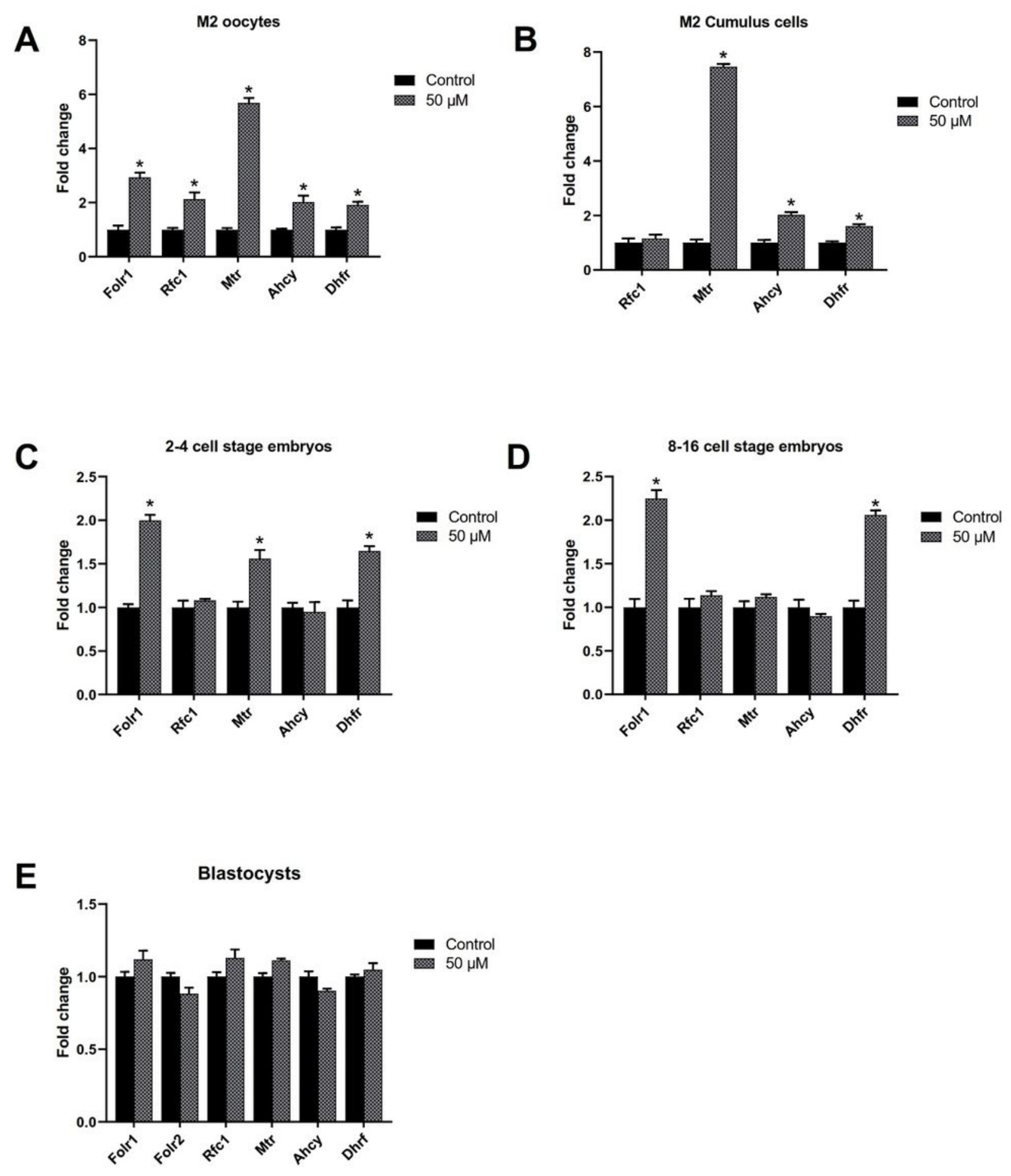

Figure 7

qRT-PCR of folate transporters and folate metabolism enzymes. The expression of folate transporters (Folr1, Folr2, Rfc1) and folate metabolism genes (Mtr, Ahcy and Dhfr) in control and $50 \mu \mathrm{M}$ folic acid supplementation group in (A) mature oocytes (M2 oocytes), (B) cumulus cells of mature oocytes (M2 cumulus), (C) 2-4 cell stage embryos, (D) 8-16 cell stage embryos and (E) blastocysts. Vertical axis represents the fold change in gene expression and horizontal axis represents the genes at control and 50 
$\mu \mathrm{M}$ folic acid supplementation. Bars represent mean number of transcripts ( $\pm \mathrm{SEM}$ ) of $\mathrm{N}=3$ repeats. Bars that have star mark $\left(^{*}\right)$ are significantly different $(P<0.05)$ by Unpaired $t$-test with Welch's correction. 